\title{
ANALISIS KEBUTUHAN PERALATAN PRAKTIK MATA KULIAH PENGERJAAN LOGAM UNTUK MENCAPAI TUNTUTAN KOMPETENSI YANG DISYARATKAN
}

\author{
Sandi Pebriyana ${ }^{1}$, Yayat ${ }^{2}$, Asep H. Sasmita ${ }^{3}$ \\ Departemen Pendidikan Teknik Mesin \\ Universitas Pendidikan Indonesia \\ Jl. Dr. Setiabudhi No. 207 Bandung 40154 \\ sandi.pebriyana@outlook.com
}

\begin{abstract}
ABSTRAK
Keterbatasan alat yang dimiliki Workshop Praktek Dasar DPTM FPTK UPI berimbas kepada pelaksanaan pembelajaran dimana sering ditemukan terjadinya antrian dalam penggunaan alat. Kondisi tersebut secara tidak langsung berpengaruh terhadap prestasi belajar mahasiswa pada mata kuliah Pengerjaan Logam. Tujuan dari penelitian ini adalah untuk mengetahui gambaran nyata tentang kondisi faktual dan kondisi ideal tentang jumlah alat, efisiensi penggunaan alat dan kondisi kesesuaian antara jumlah alat faktual dengan jumlah kebutuhan alat ideal yang digunakan pada mata kuliah Pengerjaan Logam DPTM FPTK UPI. Subjek penelitian adalah alat yang digunakan pada mata kuliah Pengerjaan Logam. Metode yang digunakan pada penelitian ini adalah metode deskriptif. Jenis instrument yang digunakan adalah pedoman dokumentasi, pedoman wawancara dan pedoman observasi. Hasil analisis data menunjukan bahwa jumlah alat yang digunakan pada pembelajaran mata kuliah Pengerjaan Logam mayoritas jumlahnya terbatas, dan nilai efisiensi penggunaan alatnya mayoritas sangat tinggi $(>90 \%)$. Perhitungan, kebutuhan alat untuk kondisi ideal pada setiap kelompok job dan nilai efisiensi penggunannya adalah: a) kerja bangku kebutuhannya 14 buah/jenis alat dengan efesiensi penggunaan $83 \%$, b) kerja plat 7 buah/jenis dengan efesiensi penggunaan $83 \%$, c) kerja las listrik 4 buah/jenis dengan efesiensi penggunaan $73 \%$, d) kerja las asetilin 7 buah/jenis dengan efesiensi $83 \%$, dan e) kerja bubut 7 buah/jenis dengan efesiensi penggunaan $83 \%$. Tingkat kesesuian antara jumlah alat yang digunakan dan jumlah kebutuhan alat yang ideal pada mata kuliah Pengerjaan Logam hanya sebesar $22 \%$.
\end{abstract}

Kata kunci: efisiensi, kompetensi, fabrikasi, logam, rasio

\section{PENDAHULUAN}

Departemen Pendidikan Teknik Mesin (DPTM) adalah salah satu unit kerja yang terdapat di lingkungan Fakultas Pendidikan Teknologi dan Kejuruan (FPTK) Universitas Pendidikan Indonesia (UPI). DPTM diproyeksikan untuk mencetak calon guru teknologi kejuruan di bidang Teknik Mesin dengan kekhasan bidang yang spesifik, yakni Teknik Pemesinan, Otomotif, serta Refrigrasi dan Tata Udara. Sebagai calon guru teknologi kejuruan, maka para lulusan harus dibekali dengan sejumlah kompetensi yang harus dimiliki seorang guru, yaitu kompetensi pedagogik, kompetensi profesional, kompetensi personal, dan kompetensi sosial (Burke, 1995).

\footnotetext{
${ }^{1}$ Mahasiswa Departemen Pendidikan Teknik Mesin FPTK UPI

2 Dosen Departemen Pendidikan Teknik Mesin FPTK UPI

${ }^{3}$ Dosen Departemen Pendidikan Teknik Mesin FPTK UPI
} 
Salah satu mata kuliah yang membentuk kompetensi profesional dan bersifat dasar keteknikan dan wajib diikuti oleh setiap mahasiswa DPTM sebelum memilih paket keahlian adalah mata kuliah Pengerjaan Logam. Mata kuliah ini bertujuan memberikan bekal dasar bagi mahasiswa untuk mengembangkan pengetahuan, sikap kerja dan keterampilan dalam teknologi mekanik dan dasar pemesinan (Hamalik, 2005).

Berdasarkan hasil penelusuran penulis terhadap dokumen pelaksanaan perkuliahan mata kuliah Pengerjaan Logam tahun ajaran 2013/2014, didapat suatu gambaran umum mengenai prestasi belajar mahasiswa untuk mata kuliah Pengerjaan Logam pada tahun ajaran 2013-2014. Temuan yang sering terjadi pada pelaksanaan perkuliahan Pengerjaan Logam adalah seringkali terjadi antrian pada Student Place (STP) di beberapa kelompok job (Syah, 2011). Berdasarkan temuan di atas setidaknya menimbulkan pertanyaan mengenai kelengkapan fasilitas yang terdapat di workshop praktik dasar apakah sudah memenuhi kriteria yang ditentukan oleh Permendikbud No. 49 Tahun 2014 pasal 35 ayat 2 tentang penyediaan sarana prasarana pembelajaran.

Tujuan dari penelitian ini adalah mengetahui dua kondisi yakni riil dan ideal. Kondisi tersebut terkait dengan jumlah alat dan efisiensi penggunaan peralatan. Selain itu penelitian ini untuk mengetahui kesesuaian antara kedua kondisi tersebut. Fokus sorotan yang menjadi topik bahasan dalam penelitian ini adalah mengenai fasilitas pembelajaran mata kuliah Pengerjaan Logam.

Mata kuliah Pengerjaan Logam adalah salah satu Mata Kuliah Keahlian (MKK) dengan beban sebesar 3 SKS. Perkuliahan mata kuliah ini didalamnya membahas mengenai teori-teori tentang pengukuran teknik, keselamatan kerja, pembentukan logam dengan menggunakan perkakas tangan, pengasahan alat, penyambungan logam baik lembaran maupun bukan lembaran dengan cara di las (Mulyasa, 2002). Proses pembelajaran mata kuliah ini juga memberikan latihan atau praktik dalam hal: penggunaan alat ukur, pembentukan benda kerja dengan menggunakan perkakas tangan, pengasahan alat, penyambungan logam lembaran, pengelasan dengan las asetilin maupun las busur listrik, serta aspek-aspek keselamatan kerja. Mata kuliah Pengerjaan Logam dilaksanakan di Workshop Praktik Dasar DPTM FPTK UPI.

Alat dan peralatan praktik adalah sarana penunjang yang harus dimiliki oleh sebuah institusi pendidikan khususnya pendidikan yang berbasis penguasaan keterampilan yang spesifik. Mengingat harga investasi alat terbilang relatif mahal, agar tidak menimbulkan kerugian perlu diperhitungkan efektivitas dan efisiensinya dengan cermat. Langkah awal dalam menghitung jumlah alat peralatan utama yang dibutuhkan adalah dengan 
menghitung efisiensi penggunaan alat menggunakan persamaan yang telah dimodifikasi (Sukmadinata, 2005). Hasil perhitungan efisiensi teoritis biasanya tidak terlalu sama dengan nilai efisiensi riil. Sehingga perlu dihitung nilai efisiensi riilnya dengan menggunakan Daftar Pembagian Tugas Praktik (DPTP).

\section{METODE PENELITIAN}

Metode penelitian yang digunakan pada penelitian ini adalah metode penelitian deskriptif. Penelitian ini merupakan studi kasus, sehingga tidak menguji hipotesis melainkan hanya memaparkan keadaan suatu kondisi secara riil tanpa ada manipulasi atau campur tangan yang mempengaruhi subjek penelitian. Penelitian dilaksanakan di Departemen Pendidikan Teknik Mesin (DPTM), Fakultas Pendidikan Teknologi dan Kejuruan (FPTK), Universitas Pendidikan Indonesia (UPI), khususnya pada Workshop Praktik Dasar Departemen Pendidikan Teknik Mesin, yang beralamat di Jl. Dr. Setiabudhi No. 207 Bandung, dengan subjek penelitian adalah fasilitas praktikum berupa peralatan dan mesin yang digunakan pada mata kuliah Pengerjaan Logam semester genap Tahun Ajaran 2013/2014. Teknik pengumpulan data yang digunakan yaitu Teknik Dokumentasi, Teknik Wawancara dan Teknik Observasi. Adapun jenis instrument yang digunakan adalah Pedoman Wawancara dan Pedoman Observasi.

\section{HASIL PENELITIAN}

Berikut ini dideskripsikan data mengenai jumlah alat faktual (Tabel 1, 2, 3, 4, 5) yang digunakan dalam pelaksanaan pembelajaran menurut masing-masing kelompok job.

Tabel 1. Jumlah alat dengan sebaran alat pada masing-masing kelompok job.

\begin{tabular}{|c|c|c|c|c|c|c|c|}
\hline \multirow{2}{*}{ No } & \multirow{2}{*}{ Nama Alat } & \multirow{2}{*}{$\begin{array}{c}\text { Jumlah alat } \\
\text { tersedia }\end{array}$} & \multicolumn{5}{|c|}{ Alokasi Penggunaan } \\
\hline & & & $\mathrm{KB}$ & BBT & $\mathrm{KP}$ & LL & LA \\
\hline 1 & Kikir bilah kasar & 47 & 18 & - & - & 14 & 15 \\
\hline 2 & Kikir bilah setengah halus & 7 & 7 & - & - & - & - \\
\hline 3 & Kikir bilah halus & 15 & 15 & - & - & - & - \\
\hline 4 & Mistar baja & 10 & 6 & - & 2 & 1 & 1 \\
\hline 5 & Mistar siku & 12 & 8 & - & 2 & 1 & 1 \\
\hline 6 & Jangka Sorong ketelitian $0,05 \mathrm{~mm}$ & 29 & 20 & 9 & - & - & - \\
\hline 7 & Mal Radius & 3 & 3 & - & - & - & - \\
\hline 8 & Penggores & 8 & 4 & - & 2 & 1 & 1 \\
\hline 9 & Penitik & 23 & 15 & - & 8 & - & - \\
\hline 10 & Palu Konde & 29 & 20 & - & 9 & - & - \\
\hline 11 & Pahat pipih & 4 & 4 & - & - & - & - \\
\hline 12 & Ragum & 18 & 14 & - & 2 & 1 & 1 \\
\hline 13 & Unit mesin bor dan perlengkapan & 2 & 1 & - & 1 & - & - \\
\hline 14 & Mata bor senter & 1 & 1 & 0 & - & - & - \\
\hline 15 & Mata bor spiral $\varnothing 5 \mathrm{~mm}$ & 0 & 0 & - & - & - & - \\
\hline 16 & Mata bor spiral $\varnothing 8 \mathrm{~mm}$ & 7 & 7 & - & - & - & - \\
\hline 17 & Mata bor spiral $\varnothing 10 \mathrm{~mm}$ & 0 & 0 & - & - & - & - \\
\hline 18 & Mata bor spiral $\varnothing 12 \mathrm{~mm}$ & 1 & 1 & - & - & - & - \\
\hline 19 & Mata bor spiral $\varnothing 14,5 \mathrm{~mm}$ & 0 & 0 & - & - & - & - \\
\hline 20 & Snei ukuran M16x1,5 mm & 1 & 1 & - & - & - & - \\
\hline
\end{tabular}




\begin{tabular}{|c|c|c|c|c|c|c|c|}
\hline \multirow{2}{*}{ No } & \multirow{2}{*}{ Nama Alat } & \multirow{2}{*}{$\begin{array}{c}\text { Jumlah alat } \\
\text { tersedia }\end{array}$} & \multicolumn{5}{|c|}{ Alokasi Penggunaan } \\
\hline & & & $\mathrm{KB}$ & BBT & $\mathrm{KP}$ & LL & LA \\
\hline 21 & Pengukur Kerataan & 5 & 5 & - & - & - & - \\
\hline 22 & Tangkai Snei & 13 & 13 & - & - & - & - \\
\hline 23 & Tap set ukuran M16x1,5 mm & 1 & 1 & - & - & - & - \\
\hline 24 & Tangkai Tap & 3 & 3 & - & - & - & - \\
\hline 25 & Alat pelipat & 2 & - & - & 2 & - & - \\
\hline 26 & Palu plastic & 23 & - & - & 23 & - & - \\
\hline 27 & Gunting tangan & 11 & - & - & 11 & - & - \\
\hline 28 & Bucking bar & 2 & - & - & 2 & - & - \\
\hline 29 & Mata bor $\varnothing 3 \mathrm{~mm}$ & 1 & - & - & 1 & - & - \\
\hline 30 & Meja kerja plat & 1 & - & - & 4 & - & - \\
\hline 31 & Rivet set & 1 & - & - & 1 & - & - \\
\hline 32 & Sikat kawat & 3 & - & - & 3 & - & - \\
\hline 33 & Sarung tangan las & 5 & - & - & - & 3 & 2 \\
\hline 34 & Mesin Las & 3 & - & - & - & 3 & - \\
\hline 35 & Meja kerja Las Listrik & 3 & - & - & - & 3 & - \\
\hline 36 & Gergaji tangan & 5 & - & - & - & 3 & 2 \\
\hline 37 & Sikat baja & 2 & - & - & - & 1 & 1 \\
\hline 38 & Tang penjepit & 8 & - & - & - & 3 & 3 \\
\hline 39 & Topeng Las listrik & 3 & - & - & - & 3 & - \\
\hline 40 & Masker & 0 & - & - & - & 0 & 0 \\
\hline 41 & Apron & 4 & - & - & - & 2 & 2 \\
\hline 42 & Tabung Gas Oxygen & 2 & - & - & - & - & 2 \\
\hline 43 & Tabung Gas Accetelyn & 2 & - & - & - & - & 2 \\
\hline 44 & Regulator Las & 2 & - & - & - & - & 2 \\
\hline 45 & Selang & 2 & - & - & - & - & 2 \\
\hline 46 & Pembakar & 3 & - & - & - & - & 2 \\
\hline 47 & Meja kerja Las Asetilin & 2 & - & - & - & - & 2 \\
\hline 48 & Kaca mata las Acetelyn & 7 & - & - & - & - & 7 \\
\hline \multirow[t]{5}{*}{49} & Unit Mesin Bubut dan perlengkapan: & 4 & - & 4 & - & - & - \\
\hline & -Chuck rahang tiga & 4 & - & 4 & - & - & - \\
\hline & -Kunci tool post & 2 & - & 2 & - & - & - \\
\hline & -Kunci chuck & 4 & - & 4 & - & - & - \\
\hline & -Senter putar & 5 & - & 5 & - & - & - \\
\hline 50 & Chuck bor & 1 & 1 & - & - & - & - \\
\hline 51 & Pahat rata kanan & 32 & - & 32 & - & - & - \\
\hline 52 & Kartel & 2 & - & 2 & - & - & - \\
\hline 53 & Bevel protactor & 3 & - & 3 & - & - & - \\
\hline 54 & Gerinda meja & 1 & - & 1 & - & - & - \\
\hline 55 & Kaca mata safety pemesinan & 7 & - & 7 & - & - & - \\
\hline
\end{tabular}

Tabel 2. Nilai efisiensi faktual penggunaan alat menurut kelas dan jenis job

\begin{tabular}{clccc}
\hline No. & Jenis Pekerjaan & Kelas A & Kelas B & Kelas C \\
\hline 1 & Kerja Bangku & $0 \%-1127 \%$ & $0 \%-1164 \%$ & $0 \%-1167 \%$ \\
2 & Kerja Pelat & $0 \%-564 \%$ & $0 \%-582 \%$ & $0 \%-663 \%$ \\
3 & Kerja Las Asetilin & $0 \%-564 \%$ & $0 \%-582 \%$ & $0 \%-636 \%$ \\
4 & Kerja Las Listrik & $0 \%-282 \%$ & $0 \%-291 \%$ & $0 \%-318 \%$ \\
5 & Kerja Bubut & $0 \%-282 \%$ & $0 \%-291 \%$ & $0 \%-318 \%$ \\
\hline
\end{tabular}

Tabel 3. Jumlah peralatan yang memenuhi kriteria efisiensi penggunaan alat standar

\begin{tabular}{clcccc}
\hline No. & Jenis Pekerjaan & Total Jumlah alat & \multicolumn{4}{c}{ Jumlah Alat yang Mencapai Kriteria Efisiensi } \\
& & & Kelas A & Kelas B & Kelas C \\
\hline 1 & Kerja Bangku & 24 & 4 & 4 & 3 \\
2 & Kerja Pelat & 15 & 1 & 1 & 2 \\
3 & Kerja Las Asetilin & 17 & 1 & 1 & 0 \\
4 & Kerja Las Listrik & 13 & 0 & 0 & 0 \\
5 & Kerja Bubut & 13 & 2 & 2 & 1 \\
\hline
\end{tabular}


Tabel 4. Jumlah Kebutuhan Peralatan Berdasarkan Kriteria Pengguaan Alat Ideal

\begin{tabular}{|c|c|c|c|c|c|c|c|}
\hline \multirow{2}{*}{ No } & \multirow{2}{*}{ Nama Alat } & \multicolumn{5}{|c|}{ Alokasi } & \multirow{2}{*}{$\begin{array}{c}\text { Jumlah Kebutuhan } \\
\text { Alat }\end{array}$} \\
\hline & & $\mathrm{KB}$ & BBT & $\mathrm{KP}$ & LL & LA & \\
\hline 1 & Kikir bilah kasar & 14 & - & - & 4 & 7 & 25 \\
\hline 2 & Kikir bilah setengah halus & 14 & - & - & - & - & 14 \\
\hline 3 & Kikir bilah halus & 14 & - & - & - & - & 14 \\
\hline 4 & Mistar baja & 14 & - & 7 & 4 & 7 & 32 \\
\hline 5 & Mistar siku & 14 & - & 7 & 4 & 7 & 32 \\
\hline 6 & Jangka Sorong ketelitian $0,05 \mathrm{~mm}$ & 14 & 7 & - & - & & 21 \\
\hline 7 & Mal radius & 14 & - & - & - & - & 14 \\
\hline 8 & Penggores & 14 & - & 7 & 4 & 7 & 32 \\
\hline 9 & Penitik & 14 & - & 7 & - & - & 21 \\
\hline 10 & Palu Konde & 14 & - & 7 & - & - & 21 \\
\hline 11 & Pahat pipih & 14 & - & - & - & - & 14 \\
\hline 12 & Ragum & 14 & - & 7 & 4 & 7 & 32 \\
\hline 13 & Unit mesin bor dan perlengkapan & 14 & - & 7 & - & - & 21 \\
\hline 15 & Mata bor spiral $\emptyset 5 \mathrm{~mm}$ & 14 & - & - & - & - & 14 \\
\hline 16 & Mata bor spiral $\varnothing 8 \mathrm{~mm}$ & 14 & - & - & - & - & 14 \\
\hline 17 & Mata bor spiral $\varnothing 10 \mathrm{~mm}$ & 14 & - & - & - & - & 14 \\
\hline 18 & Mata bor spiral $\varnothing 12 \mathrm{~mm}$ & 14 & - & - & - & - & 14 \\
\hline 19 & Mata bor spiral $\varnothing 14,5 \mathrm{~mm}$ & 14 & - & - & - & - & 14 \\
\hline 20 & Snei ukuran M16x1,5 mm & 14 & - & - & - & - & 14 \\
\hline 21 & Pengukur kerataan & 14 & - & - & - & - & 14 \\
\hline 22 & Tangkai Snei & 14 & - & - & - & - & 14 \\
\hline 23 & Tap set ukuran M16x1,5 mm & 14 & - & - & - & - & 14 \\
\hline 24 & Tangkai Tap & 14 & - & - & - & - & 14 \\
\hline 25 & Alat pelipat & - & - & 7 & - & - & 7 \\
\hline 26 & Palu plastik & - & - & 7 & - & - & 7 \\
\hline 27 & Gunting tangan & - & - & 7 & - & - & 7 \\
\hline 30 & Meja kerja plat & - & - & 7 & - & - & 7 \\
\hline 31 & Rivet set & - & - & 7 & - & - & 7 \\
\hline 32 & Sikat kawat & - & - & 7 & - & - & 7 \\
\hline 33 & Sarung tangan las & - & - & - & 4 & 7 & 11 \\
\hline 34 & Mesin Las & - & - & - & 4 & - & 4 \\
\hline 35 & Meja kerja Las Listrik & - & - & - & 4 & - & 4 \\
\hline 36 & Gergaji tangan & - & - & - & 4 & 7 & 11 \\
\hline 37 & Sikat baja & - & - & - & 4 & 7 & 4 \\
\hline 38 & Tang penjepit & - & - & - & 4 & 7 & 4 \\
\hline 39 & Topeng Las listrik & - & - & - & 4 & - & 4 \\
\hline 40 & Masker & - & - & - & 4 & 7 & 11 \\
\hline 41 & Apron & - & - & - & 4 & 7 & 11 \\
\hline 42 & Tabung Gas Oxygen & - & - & - & - & 7 & 7 \\
\hline 43 & Tabung Gas Accetelyn & - & - & - & - & 7 & 7 \\
\hline 44 & Regulator Las & - & - & - & - & 7 & 7 \\
\hline 45 & Selang & - & - & - & - & 7 & 7 \\
\hline 46 & Pembakar & - & - & - & - & 7 & 7 \\
\hline 47 & Meja kerja Las Asetilin & - & - & - & - & 7 & 7 \\
\hline \multirow[t]{3}{*}{48} & Kaca mata las Acetelyn & - & - & - & - & 7 & 7 \\
\hline & Unit Mesin Bubut dan perlengkapan: & - & 7 & - & - & - & 7 \\
\hline & -Chuck rahang tiga & - & 7 & - & - & - & 7 \\
\hline \multirow[t]{3}{*}{49} & -Kunci tool post & - & 7 & - & - & - & 7 \\
\hline & -Kunci chuck & - & 7 & - & - & - & 7 \\
\hline & -Senter putar & - & 7 & - & - & - & 7 \\
\hline 50 & Chuck bor & - & 7 & - & - & - & 7 \\
\hline 51 & Pahat rata kanan & - & 32 & - & - & - & 32 \\
\hline 52 & Kartel & - & 7 & - & - & - & 7 \\
\hline 53 & Bevel protactor & - & 7 & - & - & - & 7 \\
\hline 54 & Gerinda meja & - & 7 & - & - & - & 7 \\
\hline 55 & Kaca mata safety pemesinan & - & 7 & - & - & - & 7 \\
\hline
\end{tabular}


Tabel 5. Nilai Efisiensi Penggunaan Peralatan Sesuai dengan Jenis Job

\begin{tabular}{clcc}
\hline \multirow{2}{*}{ No. } & \multirow{2}{*}{ Jenis Job } & \multicolumn{2}{c}{ Modul 32} \\
\cline { 3 - 4 } & & Alat & Ef \\
\hline 1 & Kelompok Kerja Bangku & 15 & $83 \%$ \\
2 & Kelompok Kerja Pelat & 8 & $83 \%$ \\
3 & Kelompok Kerja Las Asetilin & 8 & $83 \%$ \\
4 & Kelompok Kerja Las Listrik & 4 & $73 \%$ \\
5 & Kelompok Kerja Bubut & 8 & $83 \%$ \\
\hline
\end{tabular}

Tabel 6. Kesesuaian peralatan yang dibutuhkan dan jenis peralatan yang tersedia

\begin{tabular}{|c|c|c|c|c|c|}
\hline No & Nama Alat & $\begin{array}{c}\text { Jumlah } \\
\text { alat } \\
\text { tersedia }\end{array}$ & $\begin{array}{c}\text { Jumlah } \\
\text { Kebutuhan } \\
\text { Alat } \\
\end{array}$ & Ket. & Kriteria \\
\hline 1 & Kikir bilah kasar & 47 & 25 & +22 & Sesuai \\
\hline 2 & Kikir bilah setengah halus & 7 & 14 & -7 & Tdk. sesuai \\
\hline 3 & Kikir bilah halus & 15 & 14 & +1 & Sesuai \\
\hline 4 & Mistar baja & 10 & 32 & -22 & Tdk. sesuai \\
\hline 5 & Mistar siku & 12 & 32 & -20 & Tdk. sesuai \\
\hline 6 & Jangka Sorong ketelitian $0,05 \mathrm{~mm}$ & 29 & 21 & +8 & Sesuai \\
\hline 7 & Mal radius & 3 & 14 & -11 & Tdk. sesuai \\
\hline 8 & Penggores & 8 & 32 & -24 & Tdk. sesuai \\
\hline 9 & Penitik & 23 & 21 & +2 & Sesuai \\
\hline 10 & Palu Konde & 29 & 21 & +8 & Sesuai \\
\hline 11 & Pahat pipih & 4 & 14 & -10 & Tdk. sesuai \\
\hline 12 & Ragum & 18 & 32 & -14 & Tdk. sesuai \\
\hline 13 & Unit mesin bor dan perlengkapan & 2 & 21 & -19 & Tdk. sesuai \\
\hline 14 & Mata bor senter & 1 & 21 & -20 & Tdk. sesuai \\
\hline 15 & Mata bor spiral $\varnothing 5 \mathrm{~mm}$ & 0 & 14 & -14 & Tdk. sesuai \\
\hline 16 & Mata bor spiral $\varnothing 8 \mathrm{~mm}$ & 7 & 14 & -7 & Tdk. sesuai \\
\hline 17 & Mata bor spiral $\varnothing 10 \mathrm{~mm}$ & 0 & 14 & -14 & Tdk. sesuai \\
\hline 18 & Mata bor spiral $\varnothing 12 \mathrm{~mm}$ & 1 & 14 & -13 & Tdk. sesuai \\
\hline 19 & Mata bor spiral Ø 14,5 mm & 0 & 14 & -14 & Tdk. sesuai \\
\hline 20 & Snei ukuran M16x1,5 mm & 1 & 14 & -13 & Tdk. sesuai \\
\hline 21 & Pengukur kerataan & 5 & 14 & -9 & Tdk. sesuai \\
\hline 22 & Tangkai Snei & 13 & 14 & -1 & Tdk. sesuai \\
\hline 23 & Tap set ukuran M16x1,5 mm & 1 & 14 & -13 & Tdk. sesuai \\
\hline 24 & Tangkai Tap & 3 & 14 & -11 & Tdk. sesuai \\
\hline 25 & Alat pelipat & 2 & 7 & -5 & Tdk. sesuai \\
\hline 26 & Palu plastik & 23 & 7 & +16 & Sesuai \\
\hline 27 & Gunting tangan & 11 & 7 & +4 & Sesuai \\
\hline 28 & Bucking bar & 2 & 7 & -5 & Tdk. sesuai \\
\hline 29 & Mata bor $\varnothing 3 \mathrm{~mm}$ & 1 & 7 & -6 & Tdk. sesuai \\
\hline 30 & Meja kerja plat & 1 & 7 & -6 & Tdk. sesuai \\
\hline 31 & Rivet set & 1 & 7 & -6 & Tdk. sesuai \\
\hline 32 & Sikat kawat & 3 & 7 & -4 & Tdk. sesuai \\
\hline 33 & Sarung tangan las & 5 & 11 & -6 & Tdk. sesuai \\
\hline 34 & Mesin Las & 3 & 4 & -1 & Tdk. sesuai \\
\hline 35 & Meja kerja Las Listrik & 3 & 4 & -1 & Tdk. sesuai \\
\hline 36 & Gergaji tangan & 5 & 11 & -6 & Tdk. sesuai \\
\hline 37 & Sikat baja & 2 & 4 & -2 & Tdk. sesuai \\
\hline 38 & Tang penjepit & 8 & 4 & +4 & Sesuai \\
\hline 39 & Topeng Las listrik & 3 & 4 & -1 & Tdk. sesuai \\
\hline 41 & Apron & 4 & 4 & 0 & Sesuai \\
\hline 42 & Tabung Gas Oxygen & 2 & 7 & -5 & Tdk. sesuai \\
\hline 43 & Tabung Gas Accetelyn & 2 & 7 & -5 & Tdk. sesuai \\
\hline 44 & Regulator Las & 2 & 7 & -5 & Tdk. sesuai \\
\hline
\end{tabular}




\begin{tabular}{llcccc}
\hline No Nama Alat & \multicolumn{1}{c}{$\begin{array}{c}\text { Jumlah } \\
\text { alat } \\
\text { tersedia }\end{array}$} & $\begin{array}{c}\text { Jumlah } \\
\text { Kebutuhan } \\
\text { Alat }\end{array}$ & Ket. & Kriteria \\
\hline 45 & Selang & 2 & 7 & -5 & Tdk. sesuai \\
46 & Pembakar & 3 & 7 & -4 & Tdk. sesuai \\
47 & Meja kerja Las Asetilin & 2 & 7 & -5 & Tdk. sesuai \\
48 & Kaca mata las Acetelyn & 7 & 7 & 0 & Sesuai \\
49 & Unit Mesin Bubut & 4 & 7 & -3 & Tdk. Sesuai \\
& perlengkapan: & 4 & 7 & -3 & Tdk sesuai \\
& -Chuck rahang tiga & 4 & 7 & -3 & Tdk sesuai \\
& -Kunci tool post & 2 & 7 & -5 & Tdk sesuai \\
& -Kunci chuck & 4 & 7 & -3 & Tdk sesuai \\
& -Senter putar & & & & Tdk. Sesuai \\
50 & Chuck bor & 1 & 7 & -6 & Sesuai \\
51 & Pahat rata kanan & 32 & 32 & 0 & Tdk. sesuai \\
52 & Kartel & 2 & 7 & -5 & Tdk. sesuai \\
53 & Bevel protactor & 3 & 7 & -4 & Tdk. sesuai \\
54 & Gerinda meja & 1 & 7 & -6 & Sesuai \\
55 & Kaca mata safety pemesinan & 7 & 7 & 0 & \\
\hline
\end{tabular}

\section{PEMBAHASAN}

Setelah dilakukan pendistribusian alat berdasarkan kelompok job, diketahui terdapat kelompok job yang memiliki jenis peralatan yang jumlahnya sedikit bahkan tidak ada alatnya. Pendistribusian jenis alat yang digunakan pada beberapa jenis job lebih beresiko untuk terjadinya ketidakmerataan distribusi (Syafrudie, 2004). Terlebih untuk kelompok job yang memiliki alokasi waktu penggunaan yang lebih besar. Perhitungan nilai efisiensi dari masing masing kelas, Jumlah kelas yang dihitung nilai efisiensi faktualnya (Tabel 2) sebanyak tiga kelas dengan jumlah masing-masing mahasiswa dalam kelas. Kelas A sebanyak 31 Mahasiswa, kelas B sebanyak 32 Mahasiswa, dan kelas C sebanyak 35 Mahasiswa. Mayoritas dari nilai efisiensi penggunaan alat yang diperoleh, menunjukan nilainya berada di luar dari kriteria efisiensi penggunaan alat standar (70-90\%).

Mayoritas jumlah alat yang memenuhi kriteria efisiensi penggunaan standar (Tabel 3) pada masing-masing kelompok job masih sangat rendah. Terlebih untuk alat pada kelompok job las listrik, dari ketiga skema kelas yang diterapkan sama sekali tidak ada satu pun peralatan yang memenuhi kriteria efisiensi penggunaan standar (Sagala, 2009). Jumlah alat yang memenuhi kriteria efisiensi penggunaan standar pada kelompok job lainnya pun tidak lebih baik dari pencapaian nilai yang dimiliki oleh kelompok job las listrik. Jumlahnya masih sangat kurang.

Hasil perhitungan jumlah kebutuhan peralatan ideal (Tabel 4) guna menunjang pembelajaran mata kuliah Pengerjan Logam berdasarkan kriteria efisiensi penggunaan peralatan yang ditentukan dengan jenis modul yang digunakan adalah modul 32 . Umumnya jumlah kebutuhan untuk masing-masing alat untuk setiap kelompok job adalah 
sama. Namun terdapat beberapa jenis alat yang jumlah kebutuhannya menjadi lebih banyak karena digunakan untuk beberapa kelompok job yang berbeda secara dalam waktu yang sama. Sehingga menjadikan jumlah alat yang harus disediakan lebih banyak.

Pengecekan nilai efisiensi perlu tersebut dilakukan untuk mengecek apakah masuk ke dalam kriteria efisiensi ideal atau tidak karena pada saat menghitung jumlah kebutuhan alat dilakukan proses pembulatan. Nilai efisiensi penggunaan peralatan (Tabel 5) untuk masing-masing kelompok job berada dalam range kriteria ideal karea berkisar Antara 70\% $-90 \%$. Kesesuaian jenis ini didasarkan pada hasil perhitungan jumlah peralatan faktual dan jumlah kebutuhan peralatan ideal (Tabel 6). Kedua data tersebut kemudian dibandingkan untuk mengetahui apakah jumlah alat yang ada sudah sesuai dengan kondisi ideal yang dihitung sebelumnya (Achir, t.t). Sebanyak 55 jenis alat yang dibutuhkan dan digunakan, tingkat kesesuaiannya hanya sebesar 22\% (12 buah alat) saja. Sisanya berada dalam kategori tidak sesuai karena keterbatasan dari jumlah alat tersebut.

\section{KESIMPULAN}

Kesimpulan penelitian ini, sebagai berikut: mayoritas alat yang digunakan pada pembelajaran mata kuliah Pengerjaan Logam jumlahnya terbatas dan terdapat beberapa jenis alat yang tidak tersedia. Mayoritas nilai efisiensi penggunaan alat memiliki nilai diluar dari kriteria efisinsi penggunaan alat standar yang ditentukan dan berada pada kategori tidak efisien. Jumlah kebutuhan ideal alat yang harus disediakan guna menunjang kegiatan pembelajaran, adalah: a) untuk kelompok job kerja bangku adalah sebanyak 14 buah/jenis alat, b) untuk kerja plat 7 buah/jenis, kerja las listrik 4 buah/jenis, c) untuk kerja las asetilin 7 buah/jenis; dan d) kerja bubut 7 buah/jenis. Nilai efisiensi penggunaan alat hasil perhitungan kebutuhan alat ideal pada masing-masing kelompok job masuk kedalam kriteria nilai efisiensi penggunaan alat standar. Hanya sebagian kecil jenis alat yang memiliki kesesuian antara jumlah alat yang digunakan dengan jumlah kebutuhan alat ideal.

\section{DAFTAR PUSTAKA}

Achir, B. (t.t). Merencanakan Kebutuhan Program Praktek dan Optimalisasi Pemakaian. Bandung: P3GT.

Burke, J. (1995) Competence Based Education. Great Britain: British Cataloging Publication Data.

Hamalik, O. (2005). Kurikulum dan Pembelajaran. Jakarta: Bumi Aksara. 
Mulyasa, E. (2002). Kurikulum berbasis kompetensi (konsep, karakteristik dan implementasi). Bandung: PT. Remaja Rosda Karya.

Sagala, S. (2009). Konsep dan Makna Pembelajaran. Bandung: CV Alfabeta.

Sukmadinata, N. S. (2005). Landasan Psikologis Proses Pendidikan. Bandung: PT. Remaja Rosda Karya.

Syafrudie, dkk. (2004). Standar minimal laboratorium, workshop, dan studio endidikan teknologi kejuruan jenjang S1. Jakarta: Departemen Pendidikan Nasional.

Syah, M. (2011). Psikologi pendidikan dengan pendekatan baru. Bandung: PT Remaja Rosda Karya. 